\title{
Blockade of B-cell activating factor with TACI-IgG effectively reduced Th1 and Th17 cells but not memory $T$ cells in experimental allergic encephalomyelitis mice
}

\author{
XIAOQIAN WANG, HE XIAO, YINXIANG WEI, XIAOLING LIU, GENCHENG HAN, \\ GUOJIANG CHEN, CHUNMEI HOU, BEIFEN SHEN, YAN LI, RENXI WANG \\ Laboratory of Immunology, Institute of Basic Medical Sciences, Beijing, China
}

\begin{abstract}
$B$-cell activating factor (BAFF) is regarded as a new therapeutic target in autoimmune diseases such as systemic lupus erythematosus (SLE) and multiple sclerosis (MS). Along with other researchers, we have demonstrated that BAFF inhibitor atacicept (TACI-IgG) suppresses lupus and experimental allergic encephalomyelitis (EAE) by reducing the mature B-cell number but not memory $B$ cells. It is however unclear whether TACI-Ig affects pathogenic T cells and memory T cells. In the present study, we found that blocking BAFF with TACI-IgG effectively reduces the pathogenic Th1 and Th17 cells in EAE mice. However, TACI-IgG did not reduce memory CD62L $\mathrm{L}^{+} \mathrm{CD} 44^{\text {hi }} \mathrm{CD} 4^{+}$and $C D 62 \mathrm{~L}^{+} \mathrm{CD} 44^{\text {hi }} \mathrm{CD} 8^{+}$ $T$ cells in EAE mice. When interleukin (IL)-15 was neutralized, memory CD62L $L^{+} C D 44^{h i} T$ cells were significantly reduced in TACI-IgG-treated EAE mice. These results suggest that TACI-IgG is effective in effective controlling Th1 and Th17 cells, but it also increases IL-15 to upregulate memory T cells in EAE mice. The study provides hints for the clinical application of the combination of BAFF-and IL-15-specific therapeutic agents.
\end{abstract}

Key words: TACI-IgG, EAE, BAFF, Th1, Th17, IL-15.

(Centr Eur J Immunol 2015; 40 (2): 142-148)

\section{Introduction}

The pathogenic role of the B-cell activating factor (BAFF) was clearly demonstrated through the development of a lupus-like illness with the production of antiDNA antibodies and the development of glomerulonephritis in BAFF-transgenic mice [1-3]. This was followed by the observation that BAFF blockage delayed systemic lupus erythematosus (SLE) onset in SLE models [2] and the subsequent discovery that patients with SLE have high serum levels of BAFF and APRIL (a proliferating-inducing ligand). B-cell activating factor level in some studies is correlated with disease activity [4] and as such, BAFF has been regarded as a new therapeutic target in SLE [5].

Belimumab, a fully human anti-BAFF monoclonal antibody, selectively reduces the numbers of $\mathrm{CD} 20^{+}$naïve $\mathrm{B}$ cells, activated B cells and plasmablasts. By contrast, belimumab treatment increases memory B-cell numbers [6]. Another BAFF inhibitor atacicept (TACI-IgG) also shows similar clinical results as belimumab by binding a portion of the receptor TACI to block the effect of BAFF and
APRIL. It reduces circulating mature B-cell and plasma cell levels in the spleen and bone marrow, inhibits T-cell activation, but not memory B cells [7]. The effect of BAFF on $\mathrm{T}$ cells has been reviewed [8]. B-cell activating factor induced $\mathrm{CD}^{+} \mathrm{T}$ cell proliferation [9] and promotes Th17 cells and aggravates experimental autoimmune encephalomyelitis [10] and autoimmune arthritis [11]. TACI-IgG limited collagen-induced arthritis [12] and adjuvant-induced arthritis [13] by regulating $\mathrm{T}$ and B lymphocytes.

B-cell activating factor is expressed by astrocytes that are associated closely with BAFF-R-expressing cells [14] and within ectopic lymphoid follicles in the meninges [15] suggesting that BAFF is also a potential target in multiple sclerosis (MS). MOG-induced chronic experimental allergic encephalomyelitis (EAE) in C57BL/6 mice [16] is an animal model for MS. Our previous study has demonstrated that TACI-IgG is effective in reducing B cells, but upregulates IL-15 promoting memory B cells in treated EAE mice [17, 18]. In the present study, our data demonstrated that blockade of BAFF with TACI-IgG reduced pathogenic Th1 and Th17

Correspondence: Renxi Wang, PhD, Laboratory of Immunology, Institute of Basic Medical Sciences, Beijing 100850, China, e-mail: wang_renxi@hotmail.com 
cells but not memory CD62 $\mathrm{L}^{+} \mathrm{CD} 44^{\text {hi }} \mathrm{T}$ cells in EAE mice. In addition, neutralizing IL-15 effectively reduced memory $\mathrm{T}$ cells in TACI-IgG-treated EAE mice. These results suggest that TACI-IgG is effective in reducing pathogenic T cells but not memory $\mathrm{T}$ cells in treating EAE mice. The study provides hints for the clinical application of a combination of BAFFand IL-15-specific therapeutic agents.

\section{Material and methods}

Mice

9-week-old C57BL/6 mice (Chinese Academy of Medical Sciences, Beijing, China) were bred in our animal facilities under specific pathogen-free conditions. Care, use and treatment of mice in this study were in strict agreement with international guidelines for the care and use of laboratory animals and approved by the Animal Ethics Committee of the Beijing Institute of Basic Medical Sciences.

\section{Experimental allergic encephalomyelitis induction}

At 9 weeks of age C57B1/6 mice received a subcutaneous injection of $125 \mu \mathrm{g}$ MOG35-55 peptide (Mimotopes, Australia) emulsified $1: 1$ (vol/vol) in Complete Freund's Adjuvant containing $4 \mathrm{mg} / \mathrm{ml}$ of Mycobacterium tuberculosis H37Ra (Difco, Detroit, MI), to both flanks and the base of the tail. Pertussis toxin (300 ng in PBS; List Biological, USA) was injected intraperitoneally at the time of induction and a second dose was administered three days later. Animals were weighed, monitored and clinically assessed according to the following grading scale: $0=$ no sign; 1 = distal tail weakness; 1.5 = tail weakness and some hindlimb weakness; 2 = complete tail paralysis; $2.5=$ complete tail paralysis and partial hindlimb weakness; $3=$ complete hindlimb weakness; $3.5=$ inability to right when placed on back or significant forelimb weakness; 4 = euthanize or spontaneous death. Mice were euthanized if they lost $20 \%$ of their starting weight, displayed a clinical score of 3 for 72 hours or reached a clinical score of 3.5. Mice were examined for up to 21 days post-immunisation.

\section{Treatment of experimental allergic encephalomyelitis mice with TACI-IgG}

Experimental allergic encephalomyelitis mice were divided into the following four groups: 1) control CFA mice; 2) PBS-treated; 3) IgG-treated; 4) TACI-IgG-treated. Six EAE mice per group were $i . v$. injected with $2 \mathrm{mg} / \mathrm{kg}$ TACI-IgG (Rongchang Bio. Corp, Shandong Province, China) on day 4, 8, 12, 16 (one time per day) after EAE induction.

\section{Treatment of experimental allergic encephalomyelitis mice with TACI-IgG and anti-IL-15 antibody}

Experimental allergic encephalomyelitis mice were divided into the following two groups: 1) TACI-IgG + control antibody; 2) TACI-IgG + Anti-IL-15. Six EAE mice per group were i.v. injected with $2 \mathrm{mg} / \mathrm{kg}$ TACI-IgG and $0.5 \mathrm{mg} / \mathrm{kg}$ neutralizing anti-mouse IL-15 antibody (R\&D system, CA, USA) or isotype and species-matched IgG (JingMei Bio. Corp, Beijing, China) on day 4, 8, 12, 16 (one time per day) after EAE induction.

\section{Cytometric analysis and intracellular cytokine staining}

Cells $\left(1 \times 10^{6}\right.$ cells/sample $)$ were washed with fluorescence-activated cell sorting staining buffer (phosphate-buffered saline, $2 \%$ fetal bovine serum or $1 \%$ bovine serum albumin, $0.1 \%$ sodium azide). All samples were incubated with the $2.4 \mathrm{G} 2$ anti-Fc receptors (BD Pharmingen), prior to incubation with other Abs diluted in fluorescence-activated cell sorting buffer supplemented with $2 \%$ anti-Fc receptor $\mathrm{Ab}$. Cells were subsequently stained with fluorescence-conjugated anti-mouse CD4, CD8, CD44, and CD62L antibodies (all antibodies from eBioscience). For intracellular cytokine staining, $50 \mathrm{ng} / \mathrm{ml}$ PMA and $1 \mathrm{mg} / \mathrm{ml}$ Ionomycin (all from Sigma-Aldrich) were added followed by $1 \mathrm{mg} / \mathrm{ml}$ brefeldin $\mathrm{A}$ and $2 \mathrm{mM}$ monensin three hours later. After another two hours, cells were collected, incubated with the $2.4 \mathrm{G} 2$ anti-Fc receptors (BD Pharmingen) and stained with fluorescence-conjugated anti-mouse CD4 antibody (eBioscience). After staining, cells were washed and subsequently fixed for $20 \mathrm{~min}$ with $1 \mathrm{ml}$ fixation buffer (Fix and Perm cell permeabilization kit, eBioscience). After washing, the fixed cells were stained with fluorescence-conjugated anti-mouse IFN- $\gamma$ and IL-17 antibody (all antibodies from eBioscience). Data collection and analysis were performed on a FACS Calibur flow cytometer using CellQuest software.

\section{Statistics}

Statistics were generated using $t$-test in GraphPad Prism (version 5.0, GraphPad Software Inc., USA) and values were represented as mean \pm standard error of the mean (SEM). Results were considered statistically significant at $p<0.05$.

\section{Results}

TACI-IgG reduced pathogenic Th1 and Th17 cells in experimental allergic encephalomyelitis mice

On day 21 after TACI-IgG was used to treat EAE mice, lymphocytes from the spleen and LN were collected and an- 

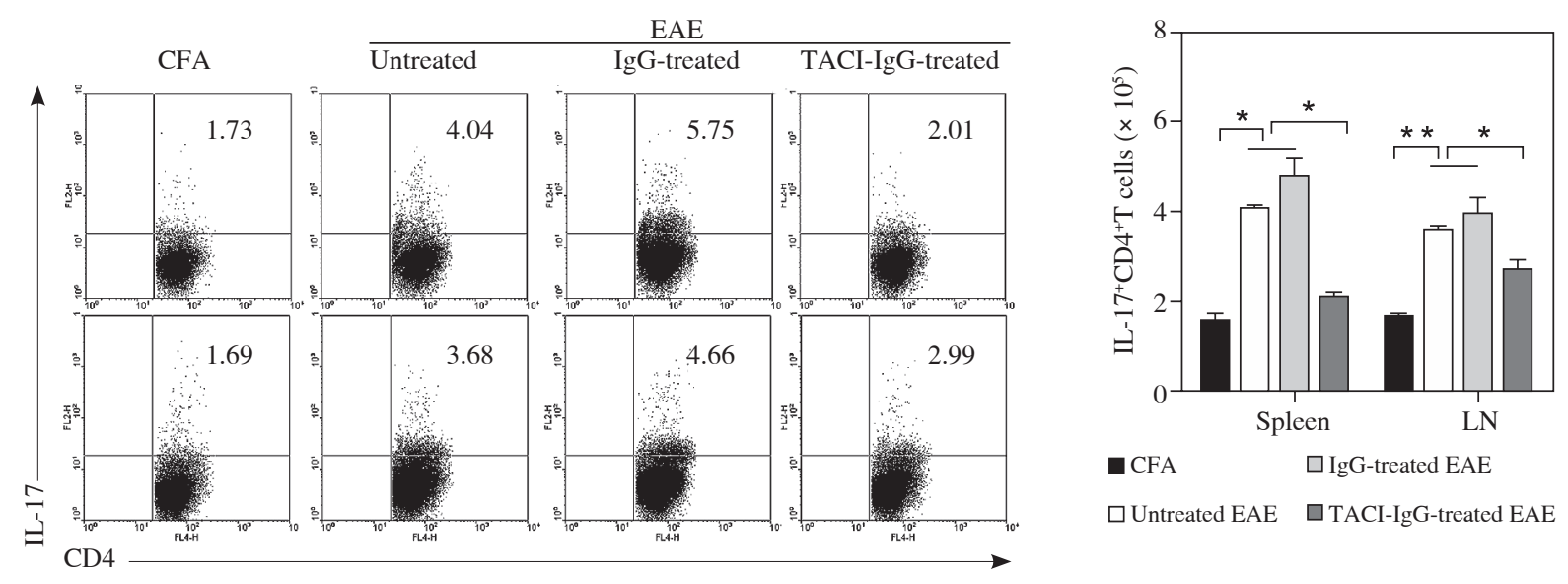

$\square$ Untreated EAE $\square$ TACI-IgG-treated EAE
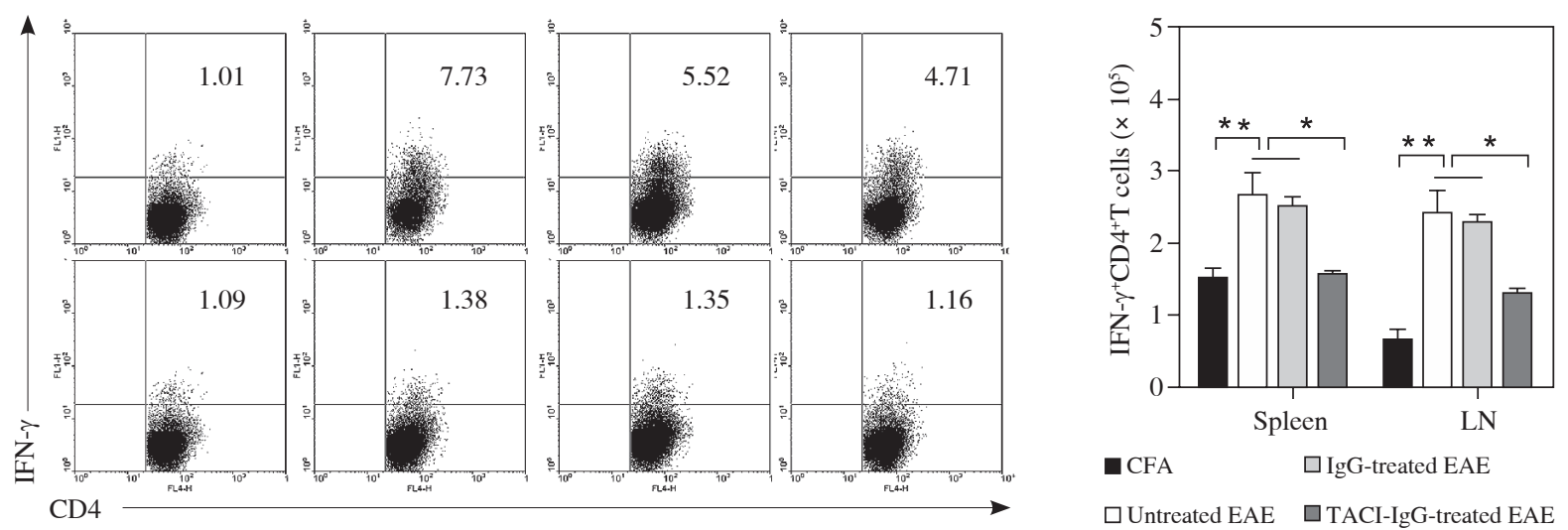

Fig. 1. TACI-IgG treatment reduced Th1 and Th17 cells in EAE mice. Six EAE mice per group were injected i.v. with $2 \mathrm{mg} / \mathrm{kg}$ TACI-IgG or isotype and species-matched IgG on day 4, 8, 12, 16 (one time per day) after EAE was induced. On day 21 after EAE induction, mice were killed and lymphocytes were collected from the spleen and the lymph node, stained with anti-mouse CD4, IL-17 and IFN- $\gamma$ antibodies, and analyzed by FACS. The percentage of $\mathrm{IL}-17^{+} \mathrm{CD} 4^{+} \mathrm{T}$, IFN $-\gamma^{+} \mathrm{CD} 4^{+} \mathrm{T}$ cells was indicated in quadrants. The right panel shows the absolute number of $\mathrm{IL}-17^{+} \mathrm{CD} 4^{+} \mathrm{T}, \mathrm{IFN}-\gamma^{+} \mathrm{CD} 4^{+} \mathrm{T}$ cells from the spleen and $\mathrm{LN}(* p<0.05, * * p<0.01)$. The data represent four independent experiments

alyzed by FACS. The percentage of $I L-17^{+} \mathrm{CD} 4^{+} \mathrm{T}$ cells in the spleen and LN from CFA mice was 1.73 and 1.69, respectively, whereas the percentage increased to 4.04 and 3.68 in the spleens and LN from EAE mice, respectively (Fig. 1). The percentage of IFN $-\gamma^{+} \mathrm{CD} 4{ }^{+} \mathrm{T}$ cells in the spleens and $\mathrm{LN}$ from CFA mice was 1.01 and 1.09, respectively, whereas the percentage increased to 7.73 and 1.38 in the spleens and LN from EAE mice, respectively (Fig. 1). In accordance with the percentage, the absolute number of $\mathrm{IL}-17^{+} \mathrm{CD} 4^{+} \mathrm{T}$ and IFN $-\gamma^{+}$Th1 cells also increased in EAE mice (Fig. 1). The results suggest that compared with CAF control, EAE mice up-regulated pathogenic Th1 and Th17 cells.

The percentage and absolute number of $\mathrm{IL}-17^{+} \mathrm{CD} 4^{+} \mathrm{T}$ and IFN- $\gamma^{+}$Th1 cells was comparable in untreated or IgG-treated EAE mice. The percentage of IL- $17^{+} \mathrm{CD} 4^{+}$ $\mathrm{T}$ cells in the spleens and $\mathrm{LN}$ from IgG-treated EAE mice was 5.8 and 4.7 , whereas the percentage reduced to 2.0 and
3.0 in the spleens and LN from TACI-IgG-treated EAE mice, respectively (Fig. 1). The percentage of IFN- $\gamma^{+} \mathrm{C}-$ $\mathrm{D}^{+}{ }^{+} \mathrm{T}$ cells in the spleens and $\mathrm{LN}$ from IgG-treated EAE mice was 5.5 and 1.4, respectively, whereas the percentage reduced to 4.7 and 1.2 in the spleens and lymph nodes (LN) from TACI-IgG-treated EAE mice, respectively (Fig. 1). In accordance with the percentage, the absolute number of IL- $17^{+} \mathrm{CD} 4^{+} \mathrm{T}$ and IFN- $\gamma^{+} \mathrm{Th} 1$ cells also reduced in TACI-IgG-treated EAE mice (Fig. 1). The results suggest that compared with IgG, TACI-IgG reduced Th1 and Th17 cells in EAE mice.

\section{TACI-IgG could not reduce memory $T$ cells in experimental allergic encephalomyelitis mice}

Previous studies have shown that belimumab or TACI-IgG treatment increases memory B-cell numbers in 
CFA
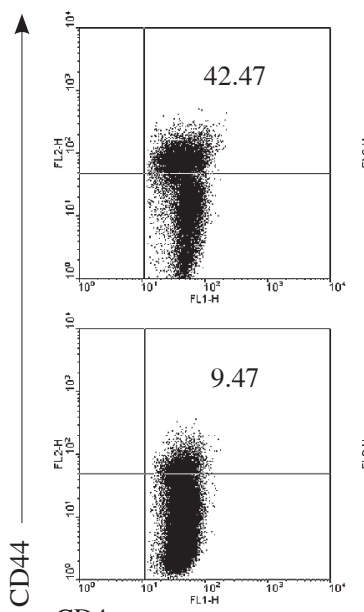

CD4
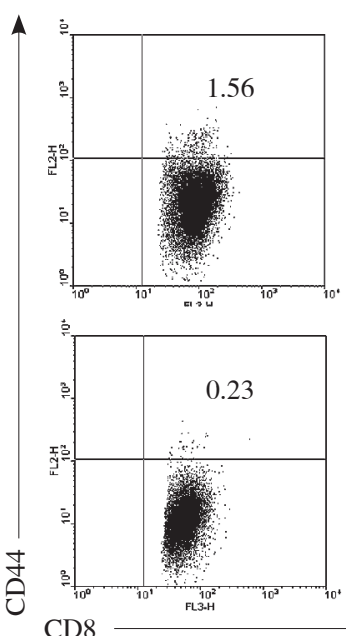
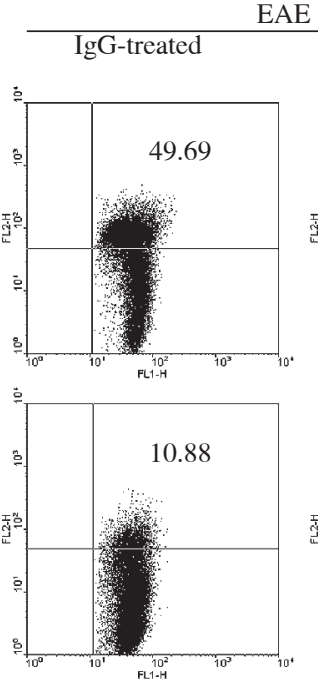

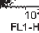
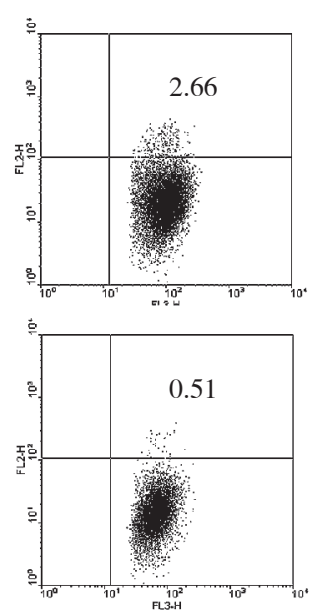

$\mathrm{EAE}$
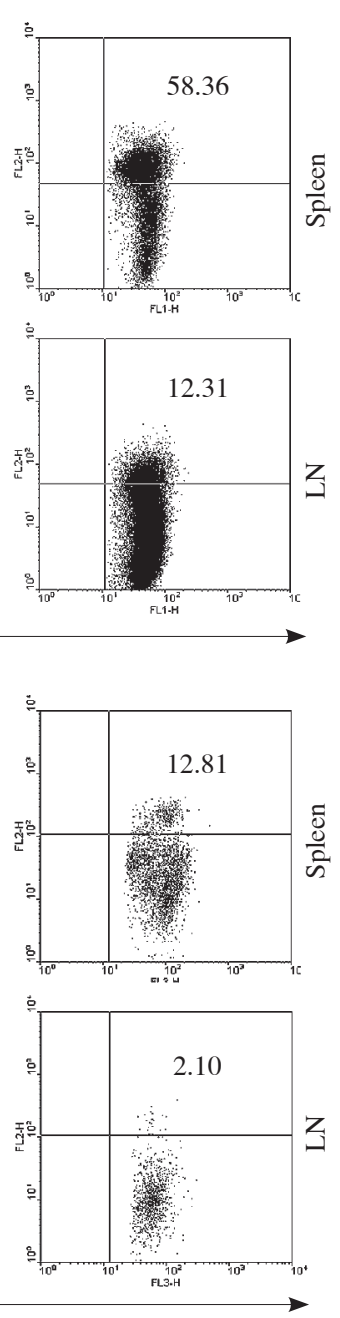

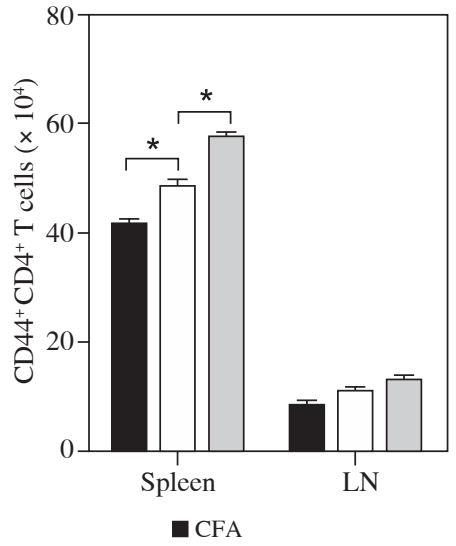

$\square$ IgG-treated EAE

$\square$ TACI-IgG-treated EAE

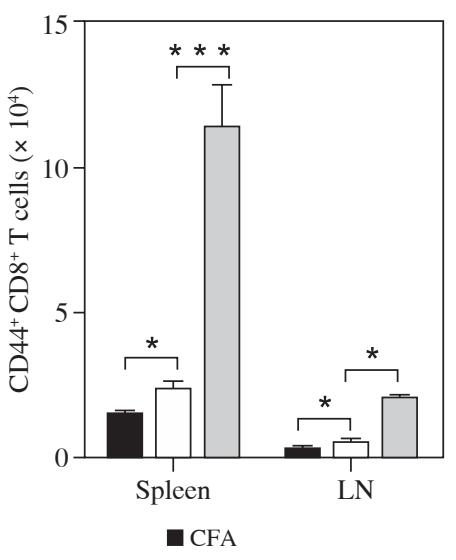

$\square$ IgG-treated EAE

口TACI-IgG-treated EAE

Fig. 2. TACI-IgG up-regulated CD44 $4^{\text {hi }}$ memory $\mathrm{T}$ cells in EAE mice. Six EAE mice per group were injected i.v. with $2 \mathrm{mg} / \mathrm{kg}$ TACI-IgG or isotype and species-matched IgG on day 4, 8, 12, 16 (one time per day) after EAE was induced. On day 21 after EAE induction, lymphocytes in the spleen and lymph nodes were collected from CFA mice, IgG or TACI-IgG-treated EAE mice. Cells were stained with anti-mouse CD62L, CD4 or CD8, CD44 antibodies. Cells were gated on $\mathrm{CD} 62 \mathrm{~L}^{+} \mathrm{CD} 4^{+}$or $\mathrm{CD} 62 \mathrm{~L}^{+} \mathrm{CD} 8^{+}$with numbers in quadrants indicating the percentage of $\mathrm{CD} 44^{\text {hi }}-$ expressing $\mathrm{CD} 4^{+}$or $\mathrm{CD} 8^{+} \mathrm{T}$ cells. The right panel shows the absolute number of $\mathrm{CD} 44^{\mathrm{hi}}-$ expressing $\mathrm{CD} 4{ }^{+}$or $\mathrm{CD} 8^{+} \mathrm{T}$ cells from the spleen and $\mathrm{LN}(* p<0.05, * * * p<0.001)$. The data represent three independent experiments

SLE patients $[6,7,17,18]$. Thus, we examine whether TACI-IgG treatment could control memory $\mathrm{T}$ cells in EAE mice. The percentage of $\mathrm{CD} 44^{\mathrm{hi}} \mathrm{CD} 62 \mathrm{~L}^{+} \mathrm{CD} 4{ }^{+} \mathrm{T}$ cells in the spleens and $\mathrm{LN}$ from IgG-treated EAE mice was 49.7 and 10.9 , respectively, whereas the percentage increased to 58.4 and 12.3 in the spleens and LN from TACI-IgG-treated EAE mice, respectively (Fig. 2). In accordance with the percentage, the absolute number of $\mathrm{CD} 44^{\mathrm{hi}} \mathrm{CD} 62 \mathrm{~L}^{+} \mathrm{C}$ $\mathrm{D}^{+} \mathrm{T}$ cells was also upregulated in TACI-IgG-treated EAE mice (Fig. 2). The results suggest that compared with IgG,
TACI-IgG expanded CD44 ${ }^{\mathrm{hi}} \mathrm{CD} 62 \mathrm{~L}^{+} \mathrm{CD} 4{ }^{+} \mathrm{T}$ memory cells in the spleen of EAE mice.

The percentage of $\mathrm{CD} 44^{\mathrm{hi}} \mathrm{CD} 62 \mathrm{~L}^{+} \mathrm{CD} 8{ }^{+} \mathrm{T}$ cells in the spleens and $\mathrm{LN}$ from $\mathrm{IgG}$-treated EAE mice was 2.7 and 0.5 , respectively, whereas the percentage increased to 12.8 and 2.1 in the spleens and LN from TACI-IgG-treated EAE mice, respectively (Fig. 2). In accordance with the percentage, the absolute number of $\mathrm{CD} 44^{\mathrm{hi}} \mathrm{CD} 62 \mathrm{~L}^{+} \mathrm{C}$ $\mathrm{D}^{+} \mathrm{T}$ cells was also upregulated in TACI-IgG-treated EAE mice (Fig. 2). The results suggest that compared with IgG, 

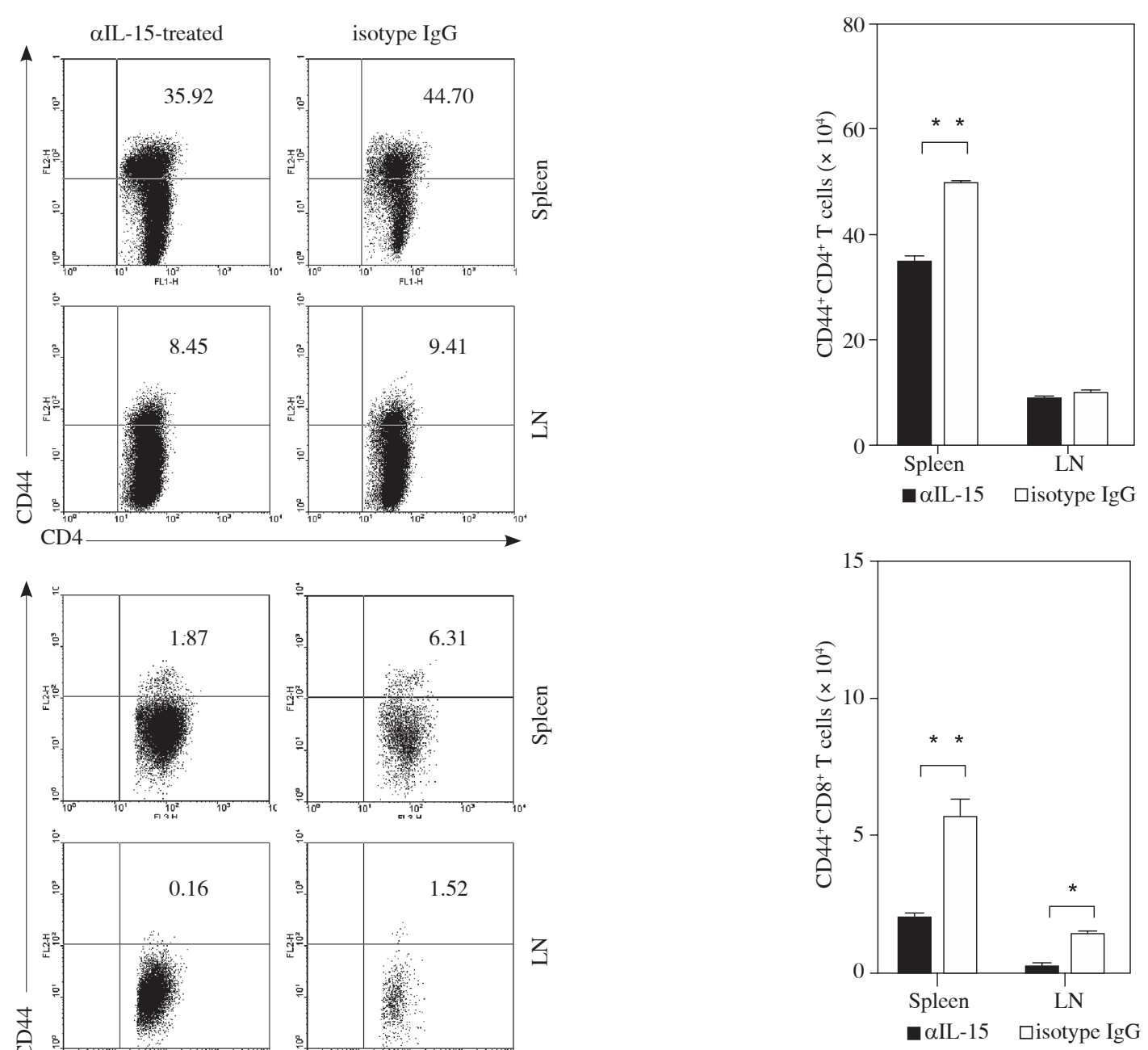

Fig. 3. Blockage of IL-15 efficiently reduced CD $44^{\text {hi }}$ memory T cells in TACI-IgG-treated EAE mice. Six EAE mice per group were injected $i . v$. with $2 \mathrm{mg} / \mathrm{kg}$ TACI-IgG plus $0.5 \mathrm{mg} / \mathrm{kg}$ neutralizing anti-mouse IL-15 antibody or isotype and species-matched $\operatorname{IgG}$ on day 4, 8, 12, 16 (one time per day) after EAE was induced. On day 21, mice were killed and lymphocytes were collected from the spleen and lymph node. Cells were stained with anti-mouse CD62L, CD4 or CD8, CD44 antibodies. Cells were gated on $\mathrm{CD}_{2} \mathrm{~L}^{+} \mathrm{CD} 4^{+}$or $\mathrm{CD} 62 \mathrm{~L}^{+} \mathrm{CD} 8^{+}$with numbers in quadrants indicating the percentage of $\mathrm{CD} 44^{\mathrm{hi}}-$ expressing $\mathrm{CD} 4^{+}$or $\mathrm{CD} 8^{+} \mathrm{T}$ cells. The right panel shows the absolute number of $\mathrm{CD}_{4} 4^{\mathrm{hi}}-$ expressing $\mathrm{CD}^{+}$or $\mathrm{CD}^{+} \mathrm{T}$ cells from the spleen and $\mathrm{LN}(* p<0.05, * * p<0.01)$. The data represent three independent experiments

TACI-IgG expanded CD44 ${ }^{\text {hi }} \mathrm{CD} 62 \mathrm{~L}^{+} \mathrm{CD} 8^{+} \mathrm{T}$ memory cells in the spleen of EAE mice.

\section{Memory T-cell-associated interleukin 15 level increased in TACI-IgG-treated experimental allergic encephalomyelitis mice}

Interleukin 15 is an important cytokine maintaining $\mathrm{T}$ memory cell survival and expansion. Our previous study demonstrated that TACI-IgG expanded memory B cells by upregulating IL-15 in lupus-like mice and EAE mice [17,
18]. Thus, we examined whether blocking IL-15 could reduce the T memory cell number in TACI-IgG-treated EAE mice. The percentage of $\mathrm{CD} 44^{\mathrm{hi}} \mathrm{CD} 62 \mathrm{~L}^{+} \mathrm{CD} 4{ }^{+} \mathrm{T}$ cells in the spleens and LN from TACI-IgG plus isotype IgG-treated EAE mice was 44.7 and 9.4, respectively, whereas the percentage reduced to 35.9 and 8.5 in the spleens and $\mathrm{LN}$ from TACI-IgG plus anti-IL-15-treated EAE mice, respectively (Fig. 3). In accordance with the percentage, the absolute number of $\mathrm{CD} 44^{\mathrm{hi}} \mathrm{CD} 62 \mathrm{~L}^{+} \mathrm{CD} 4{ }^{+} \mathrm{T}$ cells was also reduced in TACI-IgG plus anti-IL-15-treated EAE mice 
(Fig. 3). The results suggest that blockage of IL-15 reduced $\mathrm{CD} 44^{\text {hi }} \mathrm{CD} 62 \mathrm{~L}^{+} \mathrm{CD} 4{ }^{+} \mathrm{T}$ memory cells in TACI-IgG-treated EAE mice.

The percentage of $\mathrm{CD} 44^{\mathrm{hi}} \mathrm{CD} 62 \mathrm{~L}^{+} \mathrm{CD} 8+\mathrm{T}$ cells in the spleens and LN from TACI-IgG plus isotype IgG-treated EAE mice was 6.3 and 1.5 , respectively, whereas the percentage increased to 1.9 and 0.2 in the spleens and LN from ACI-IgG plus anti-IL-15-treated EAE mice, respectively (Fig. 3). In accordance with the percentage, the absolute number of $\mathrm{CD} 44^{\mathrm{hi}} \mathrm{CD} 62 \mathrm{~L}^{+} \mathrm{CD} 8{ }^{+} \mathrm{T}$ cells was also reduced in TACI-IgG plus anti-IL-15-treated-treated EAE mice (Fig. 3). The results suggest that blockade of IL-15 reduced CD44 ${ }^{\text {hi }} \mathrm{CD} 62 \mathrm{~L}^{+} \mathrm{CD} 8^{+} \mathrm{T}$ memory cells in TACI-IgG-treated EAE mice.

\section{Discussion}

B cell activating factor demonstrates specific activity toward B cells, and supports B-cell proliferation, differentiation, and survival [19]. B cell activating factor-transgenic mice harbor increased B220 $\mathrm{B}$ cells and plasma cells in the spleen and lymph nodes, and develop antidouble-stranded DNA antibodies, proteinuria, and glomerulonephritis consistent with a systemic lupus erythematosus-like autoimmunity as they age [20]. In contrast, BAFF knockout mice have a markedly reduced mature B-cell population and decreased serum Ig levels [21].

Many trials have been done to study the effect of BAFF inhibition on SLE such as belimumab (anti-BAFF antibody), and atacicept (TACI-IgG). Our previous studies [7] have shown that TACI-IgG reduce circulating mature B-cell levels. In the present study, TACI-IgG was effective in suppressing $\mathrm{T}$ cells-mediated inflammatory response such as Th1 and Th17 expansion (Fig. 1). These studies suggest that treatment of BAFF inhibitor TACI-IgG on MS may be an efficient way of suppressing effective $\mathrm{T}$ and $\mathrm{B}$ cells.

We and other researchers have demonstrated that agents designed to target BAFF failed to effectively control memory B cells $[7,17,18]$. Here, we used EAE mice to understand whether TACI-IgG control memory T cells. Our data demonstrated that TACI-IgG treatment upregulated memory T cells (Fig. 2). These studies suggest that TACI-IgG could not efficiently control immune memory. As long as the reactive memory is maintained, this is probably acceptable, as autoimmune diseases can in principle be restored from it [22].

Our previous study has demonstrated that IL-15 was upregulated in TACI-IgG-treated EAE mice and when IL-15 was neutralized, memory B cells decreased in EAE $[17,18]$. Previous studies have shown that survival signals that maintain memory $\mathrm{T}$ cells in the absence of antigen are provided by IL-15 [23, 24]. Thus, we blocked IL-15 in TACI-IgG-treated EAE mice. We found that effective blocking of IL-15 reduced CD44 ${ }^{\text {hi }} \mathrm{CD} 62 \mathrm{~L}^{+} \mathrm{T}$ memory cells in TACI-IgG-treated EAE mice.

Interleukin 15 is a dangerous inflammatory cytokine and inhibits self-tolerance by IL-2 mediated activation-induced cell death and facilitates maintenance of memory cells. Disordered IL-15 expression has been reported in patients with an array of inflammatory autoimmune diseases [25-27] including aggravated EAE disease in IL-15 knockout mice [28]. Two recent studies have shown that B cell-derived IL-15 [29] and astrocyte-derived IL-15 enhance $\mathrm{CD} 8^{+} \mathrm{T}$ cell cytotoxicity in MS patients [30]. Thus, a combination of BAFF- and IL-15-specific blocking agents will be an effective way to treat autoimmune diseases.

In conclusion, TACI-IgG was effective in reducing effective $\mathrm{T}$ cells but not memory $\mathrm{T}$ cells in EAE mice. In addition, blockage of IL-15 could reduce memory $\mathrm{T}$ cells. The study provides hints for the clinical application of a combination of BAFF- and IL-15-specific therapeutic agents for the treatment of autoimmune diseases.

This study was supported by a National Basic Research Program 973 Grant (2013CB530506), National Nature and Science Fund (81471529, 81272320 and $81172800)$ and Beijing Natural Science Foundation (7132139, 7141007 and 7132151).

The authors declare no conflict of interest.

\section{References}

1. Mackay F, Schneider P (2009): Cracking the BAFF code. Nat Rev Immunol 9: 491-502.

2. Khare SD, Sarosi I, Xia XZ, et al. (2000): Severe B cell hyperplasia and autoimmune disease in TALL-1 transgenic mice. Proc Natl Acad Sci U S A 97: 3370-3375.

3. Gross JA, Johnston J, Mudri S, et al. (2000): TACI and BCMA are receptors for a TNF homologue implicated in B-cell autoimmune disease. Nature 404: 995-999.

4. Zhang J, Roschke V, Baker KP, et al. (2001): Cutting edge: a role for B lymphocyte stimulator in systemic lupus erythematosus. J Immunol 166: 6-10.

5. Vincent FB, Morand EF, Mackay F (2012): BAFF and innate immunity: new therapeutic targets for systemic lupus erythematosus. Immunol Cell Biol 90: 293-303.

6. Liu Z, Davidson A (2013): Taming lupus-a new understanding of pathogenesis is leading to clinical advances. Nat Med 18: 871-882.

7. Carbonatto M, Yu P, Bertolino M, et al. (2008): Nonclinical safety, pharmacokinetics, and pharmacodynamics of atacicept. Toxicol Sci 105: 200-210.

8. Mackay F, Leung H (2006): The role of the BAFF/APRIL system on T cell function. Semin Immunol 18: 284-289.

9. Ji F, Chen R, Liu B, et al. (2012): BAFF induces spleen CD4+ $\mathrm{T}$ cell proliferation by down-regulating phosphorylation of FOXO3A and activates cyclin D2 and D3 expression. Biochem Biophys Res Commun 425: 854-858.

10. Wen L, Chen SJ, Zhang W, et al. (2011): hsBAFF regulates proliferation and response in cultured CD4(+) T lymphocytes 
by upregulation of intracellular free $\mathrm{Ca}(2+)$ homeostasis. Cytokine 53: 215-222.

11.Zhou X, Xia Z, Lan Q, et al. (2011): BAFF promotes Th17 cells and aggravates experimental autoimmune encephalomyelitis. PLoS One 6: e23629.

12. Liu Y, Zhang L, Wu Y, et al. (2011): Therapeutic effects of TACI-Ig on collagen-induced arthritis by regulating $\mathrm{T}$ and $\mathrm{B}$ lymphocytes function in DBA/1 mice. Eur J Pharmacol 654: 304-314.

13. Qin Q, Chang Y, Wang D, et al. (2011): TACI-Ig induces immune balance of Th cells in MLN via BLyS/APRIL-receptors signaling in rats with adjuvant-induced arthritis. Int Immunopharmacol 11: 2167-2175.

14. Krumbholz M, Theil D, Derfuss T, et al. (2005): BAFF is produced by astrocytes and up-regulated in multiple sclerosis lesions and primary central nervous system lymphoma. J Exp Med 201: 195-200.

15. Magliozzi R, Columba-Cabezas S, Serafini B, Aloisi F (2004): Intracerebral expression of CXCL13 and BAFF is accompanied by formation of lymphoid follicle-like structures in the meninges of mice with relapsing experimental autoimmune encephalomyelitis. J Neuroimmunol 148: 11-23.

16. Stromnes IM, Goverman JM (2006): Active induction of experimental allergic encephalomyelitis. Nat Protoc 1: 18101819.

17. Ma N, Xing C, Xiao H, et al. (2014): BAFF suppresses IL-15 expression in B cells. J Immunol 192: -4192.

18. Ma N, Xing C, Xiao H, et al. (2014): Combination of TACI-IgG and anti-IL-15 treats murine lupus by reducing mature and memory B cells. Cell Immunol 289: 140-144.

19. Baslund B, Tvede N, Danneskiold-Samsoe B, et al. (2003): A novel human monoclonal antibody against IL-15 (humax-IL-15) in patients with active rheumatoid arthritis (RA): results of a double-blind; placebo-controlled phase I/II trial. Arthritis Rheum Suppl S: 1706.

20. Dillon SR, Gross JA, Ansell SM, Novak AJ (2006): An APRIL to remember: Novel TNF ligands as therapeutic targets. Nat Rev Drug Discov 5: 235-246.

21. Mackay F, Woodcock SA, Lawton P, et al. (1999): Mice transgenic for BAFF develop lymphocytic disorders along with autoimmune manifestations. J Exp Med 190: 1697-1710.

22. Yoshida T, Mei H, Dörner T, et al. (2010): Memory B and memory plasma cells. Immunol Rev 237: 117-139.

23. Purton JF, Tan JT, Rubinstein MP, et al. (2007): Antiviral CD4+ memory T cells are IL-15 dependent. J Exp Med 204: 951-961.

24. Weng NP, Liu K, Catalfamo M, et al. (2002): IL-15 is a growth factor and an activator of CD8 memory T cells. Ann N Y Acad Sci 975: 46-56.

25. Villadsen LS, Schuurman J, Beurskens F, et al. (2003): Resolution of psoriasis upon blockade of IL-15 biological activity in a xenograft-mouse model. J Clin Invest 112: 1571-1580.

26. Mention JJ, Ben Ahmed M, Bčgue B, et al. (2003): Interleukin 15: a key to disrupted intraepithelial lymphocyte hemostasis and lymphomagenesis in celiac disease. Gastroenterology 125: 730-745.

27. Gross JA, Dillon SR, Mudri S, et al. (2001): TACI-Ig neutralizes molecules critical for B cell development and autoimmune disease. Impaired B cell maturation in mice lacking BLyS. Immunity 15: 289-302.

28. Gresle MM, Shaw G, Jarrott B, et al. (2008): Validation of a novel biomarker for acute axonal injury in experimental autoimmune encephalomyelitis. J Neurosci Res 86: 3548-3555.
29. Butzkueven H, Emery B, Cipriani T, et al. (2006) Endogenous leukemia inhibitory factor production limits autoimmune demyelination and oligodendrocyte loss. Glia 53: 696-703.

30. Amadi-Obi A, Yu CR, Liu X, et al. (2007): TH17 cells contribute to uveitis and scleritis and are expanded by IL-2 and inhibited by IL-27/STAT1. Nat Med 13: 711-718. 